\title{
Converses amb Enric Valls Giménez
}

\author{
Entrevistat per Josep Maria Pons i Altés
}

\author{
Universitat Rovira i Virgili
}

Nascut a Reus, va obtenir a la Universitat de Barcelona els títols de Llicenciat en Filosofia i Lletres -Secció Psicologia, de Llicenciat en Història Moderna i Contemporània i de Doctor en Psicologia.

Va exercir com a professor d'EGB i de batxillerat. Des de 1976 fins al setembre de 2015 ha estat professor universitari, a l'Escola de Mestres de Tarragona i a la Facultat de Ciències de l'Educació i Psicologia de la URV. S'ha dedicat preferentment a la formació de mestres, impartint matèries de la seva àrea de coneixement, la de psicologia evolutiva i de l'educació del Departament de Psicologia de la URV. També fou consultor de la UOC durant els seus deu primers anys de funcionament.
Ha format part d'un grup consolidat de recerca, amb professorat d'universitats catalanes, $\mathrm{i}$ és autor de treballs sobre l'aprenentatge i ensenyança dels continguts procedimentals del currículum escolar, sobre l'assessorament psicopedagògic $\mathrm{i}$, darrerament, sobre el desenvolupament $\mathrm{i}$ avaluació de capacitats i competències bàsiques.

Ha col-laborat amb administracions i institucions educatives en activitats relacionades amb l’elaboració de dissenys curriculars, amb la concreció de les competències bàsiques de l'escolaritat obligatòria, en la coordinació de cursos d'especialització de mestres i en la formació permanent del professorat.

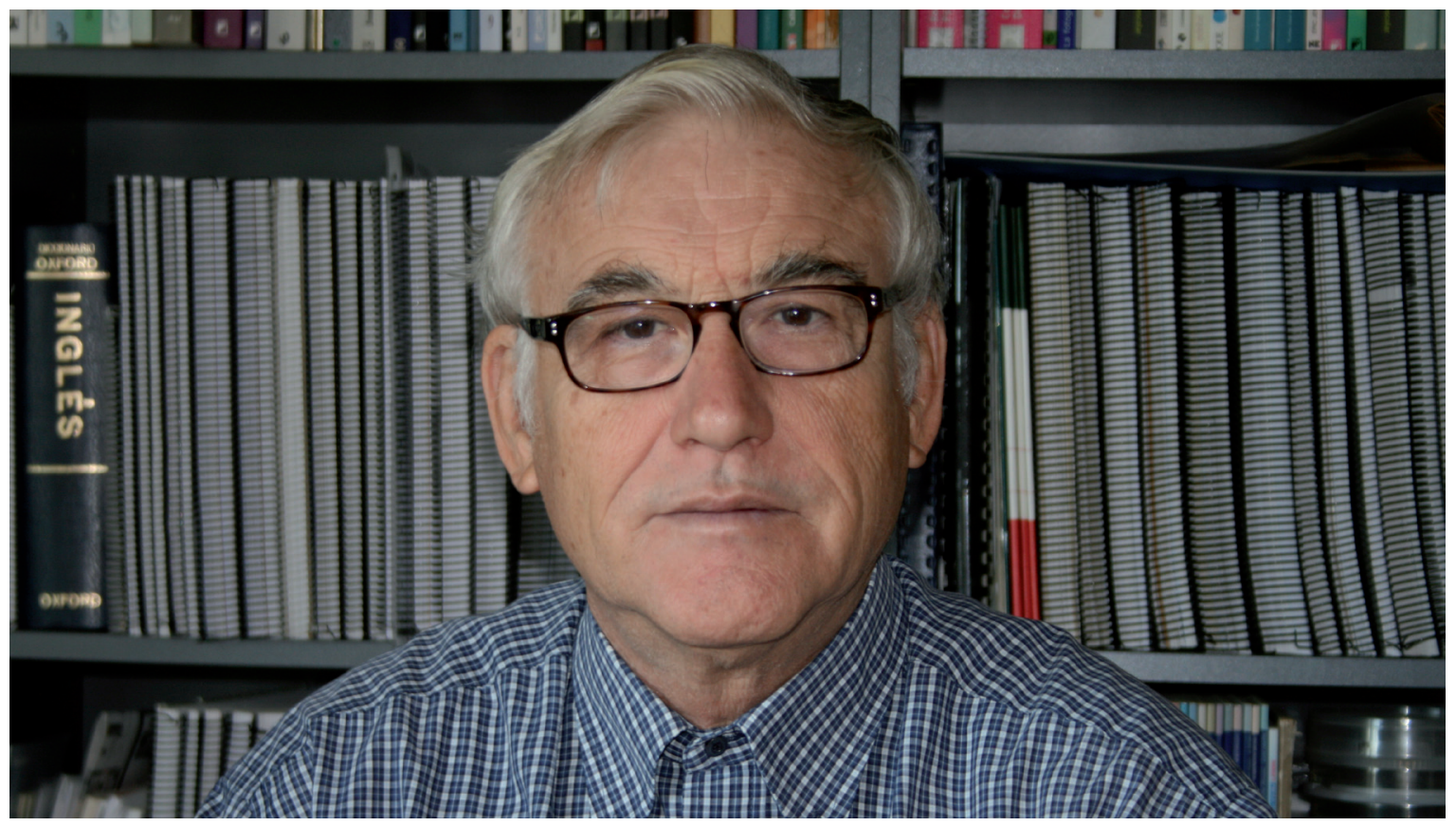


El teu perfil professional és molt interessant en una Facultat que forma professionals de l'ensenyament bàsic: de mestre, a mestre de mestres. Explica'ns els teus primers passos en el món de la docència.

En primer lloc, deixeu-me agrair que des de la revista em privilegieu amb aquest reconeixement. No em considero persona amb trajectòria, pensaments o opinions rellevants pel que fa a la formació de mestres, l'escola, l'educació, per ferme mereixedor d'entrevistes com aquesta. Gràcies, doncs.

Responent a la primera demanda que em fas, he de dir que vaig fer de mestre al Col-legi La Salle de Reus al llarg de cinc anys, a primària (llavors EGB) i, també, a batxillerat. Estant per Reus, amb molts antics alumnes encara intercanviem records del que fèiem a les classes de Ciències Socials, de Llengua i Literatura, de Llatí i de Grec -que els vaig aprendre al Seminari de Tarragona-, o a les hores de pati jugant amb ells a futbol, mitja part amb cada equip... Tenim molts records agradables d'aquella època. Estic parlant dels anys setanta del segle passat.

\section{I la teva formació acadèmica universitària?}

Bons records, també. Acabava la jornada laboral a les $5 \mathrm{i}$, llavors, tres companyes i jo agafàvem el cotxe i corre que corre cap a Barcelona per arribar a les classes de la tarda, de les 7 a les 10 de la nit. Era una sort que les aules de la UB estaven a l'entrada de la Diagonal. Primer, vaig acabar la llicenciatura en Filosofia i Lletres, secció Psicologia, tenint com a professors Siguán, Aragó, Folch i Camarasa, Batallé, entre d'altres. Com que sospitava que això de la psicologia llavors no donava per molt, a continuació vaig cursar la llicenciatura d'Història Moderna i Contemporània, amb professors com Termes, Aracil, Vilanova, entre d'altres. Per què vaig triar fer Història? Per poder fer més bé - deia- les classes de Ciències Socials al col-legi.

Aquesta darrera intenció no l'he pogut dur a terme mai, perquè tot just acabada la llicenciatura, al setembre de 1976, em varen trucar per si volia fer de professor de Psicologia a l'Escola de Mestres de Tarragona. No he sabut ben bé mai com es va originar la proposta. Vaig tenir una en- trada una mica sorprenent: si al setembre, abans de començar les classes, només tenia assignades unes poques hores, a loctubre ja tenia assignat horari complet, per la marxa del professor titular a altra destinació. Hi exercí de PNN (professor no numerari) fins a treure les oposicions a professor titular, el 1984, i a catedràtic d'escola universitària, el 1992.

La tesi doctoral la vas fer amb un dels màxims exponents de l'educació del moment com és Cèsar Coll. Què vas voler investigar $i$ demostrar amb aquella recerca?

A les acaballes dels vuitanta vaig fer els cursos de doctorat, on vaig tenir com a professor Cèsar Coll. De la coneixença sorgí la possibilitat de treballar amb ell, de manera que acordàrem la direcció de la tesi. Eren els temps de la Reforma educativa per excel-lència, i era un novetat la presència dels procediments en els currículums escolars. Vaig pensar que calia fonamentar amb rigor la proposta d'aprendre'ls i ensenyar-los bé, i sobre això vaig fer la recerca.

Ara, es pot considerar que els procediments estan ja enterament integrats en la planificació del treball dels docents, atès que els dissenys no els diversifiquen expressament.

Sempre he estat satisfet de l'aportació feta llavors. També, perquè em permeté compartir coneixements sobre el tema amb molts mestres i professors d'altres parts de l'Estat, participants en cursos i seminaris organitzats per centres de professors o centres de recursos: de Palència, Múrcia, Badajoz, Pamplona, Sant Sebastià, Bilbao, Zamora, Saragossa, Granada. Com veus, vaig poder fer quilòmetres per la geografia de l'Estat.

Moltes vegades, en canvi, sembla que costa portar a l'aula de l'escola els paradigmes i propostes educatives.

No voldria que exageréssim. Sí que reeixeixen a les aules escolars propostes originades en la recerca universitària. Només cal veure, per exemple, el cas de la recerca sobre la primera alfabetització, de Teberosky i altres, que ha suposat un canvi en la pràctica de l'ensenyança inicial de la lectura i escriptura; o com la teoria sobre les intel- 
ligències múltiples, de Gardner, que es fa servir per reorientar el treball de l'aula; o la importància que es dóna cada cop més a les emocions en la vida escolar; o com han canviat la concepció i pràctica de l'educació psicomotora a les escoles. Tot relacionat o derivat d'alguna manera amb recerca universitària.

Sí, però molts mestres tenen la impressió que el món universitari està completament desvinculat de la realitat escolar i que no els aporta massa coses útils. Què recomanaries per superar aquesta barrera?

Coincideixo amb tu que aquesta impressió existeix, que la recerca universitària referida a l'educatiu està una mica allunyada del món escolar. No entraré a opinar sobre les raons de tal distanciament. Sí que matreveixo, en canvi, a avançar alguna recomanació per superar aquesta barrera, tal com em demanes.

Recordo com si fos avui la súplica que en una ocasió, fa temps, em dirigí la Pia Vilarrubias, persona referent de la renovació pedagògica, tot pensant alhora en el conjunt dels formadors de mestres: "Feu de pont, sisplau, feu de pont entre un món i l'altre". Aquesta seria una recomanació: crear ponts, buscar persones que facin com de traductors, de canalitzadors del coneixement fruit de recerca universitària per oferir-lo al món escolar. Els mestres, en la immensa majoria, són professionals oberts, receptius, que volen canviar i millorar les seves pràctiques, $\mathrm{i}$ accepten de bon grat, d'entrada, qualsevol ajut. Què demanen, però? Potser ara simplificaré la cosa, però a partir de la relació que he tingut amb docents em sembla que volen que el coneixement que sofereix respongui a preocupacions reals sentides o intuïdes, que la seva presentació fugi de formalismes i que generi de manera relativament fàcil algunes mesures concretes per canviar la seva pràctica escolar quotidiana, la utilitat que deies tu. Quan la divulgació de la recerca universitària conté aquestes premisses, penso que la barrera inicial és fàcil de superar.

Es tracta, també, d'altra banda, que des del món escolar es faci demanda més expressa al món universitari de temàtiques educatives que interessa que s'investigui preferentment. Aques- ta és una mesura més coneguda, perquè moltes administracions educatives ja fixen uns quants àmbits sobre els quals fer recerca si els grups universitaris volen accedir a ajuts.

Acabes de referir-te a la teva participació en activitats de formació permanent del professorat. Quin és el balanç que en fas?

Hi ha bones tesis doctorals recents sobre l'aprofitament de la formació permanent del professorat, on es presenta una visió molt més completa del que jo pugui dir a partir de la meva experiència. Majoritàriament, he fet assessorament en activitats de formació en centre, amb professorat d'infantil, primària i secundària. En general, he vist que l'aprofitament d'aquesta modalitat de formació depenia de molts factors, que de la seva major o menor influència depenien els resultats

Assenyala alguns factors d'aquests que consideres més influents per a l'aprofitament de la formació permanent del professorat.

Ho faig a partir de la meva experiència, és clar.

Un, si bé la demanda de la temàtica a tractar en els assessoraments parteix del centre com a tal

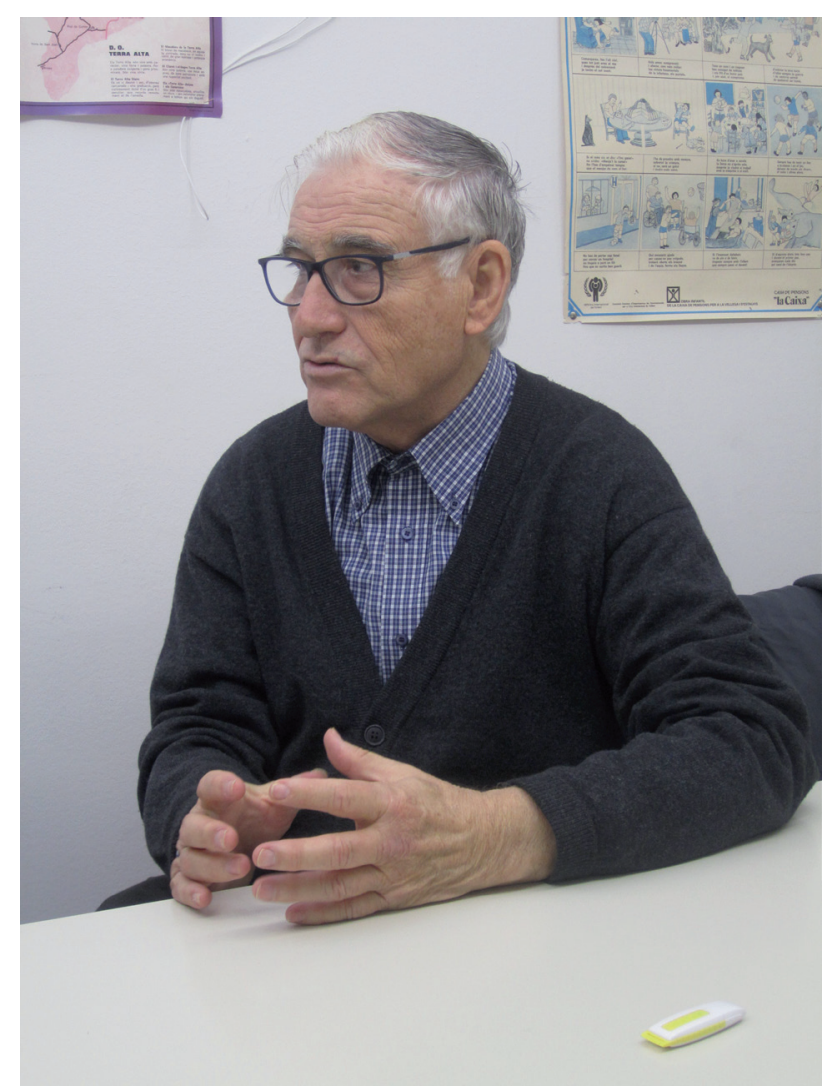


i respon a necessitats detectades, el coneixement previ i l'interès de cada mestre o professor participant envers el tema no sempre són els mateixos. El fet que hi havia punts de partida diferents influiia molt en el desenvolupament de l'activitat formativa, en un sentit o altre. Alguna vegada la convertia, per exemple, en un espai que s'aprofitava per a la discussió total, per a la contraposició continuada d'idees, a propòsit o no de la temàtica, i no s’avançava gaire.

Un altre aspecte que he constatat rellevant per al balanç: als centres on hi havia més tradició de discussió i reflexió col-lectiva i de lideratge pedagògic pot estar més assegurat l'aprofitament de la formació per part de tot el grup, i no que d'aquesta se'n beneficiïn només unes quantes persones.

D'altra banda, i parlant sincerament, he notat que dedicar-se a la formació permanent dels docents costa. Has de dominar estratègies d'accés urgent a les persones, generar confiança, posar-se en el punt de vista del mestre o professor, tenir en tot moment la pràctica com a referent, sortir al pas de resistències, ser amè, suscitar moments màgics en què l'altre tasti el canvi com a possible, ser hàbil en l'aprofitament de les inter- vencions que fan, mesurar bé la quantitat d'informació que es comparteix... Aturo la llista!

Goso dir que dedicar-se a la formació permanent dels docents hauria de ser reconegut com a professió específica, per la naturalesa de les habilitats $i$ actituds que he vist que requereix.

Parlem ara més en concret, si vols, de la teva trajectòria d'investigació

Per desgràcia - si es pot dir així- he tocat massa tecles, sense que pugui assenyalar-ne una que és la que sona millor, la meva preferida. He format part de diversos equips de recerca. Amb el grup de recerca de la UB coordinat per Cèsar Coll (amb Maite Mauri, Isabel Solé i Xavi Onrubia, entre d'altres), els treballs principals realitzats han estat sobre les pràctiques avaluatives de docents de primària i secundària de Catalunya i, més recentment, sobre formes de promoure l'aprenentatge autònom de l'estudiant i l'autoregulació individual i de grup. Amb l'equip de recerca de la UAB coordinat per Carles Monereo (amb Isabel Gómez, Montse Castelló i Magüi Pérez, entre d'altres) ens centràrem en el tema de les estratègies d'aprenentatge i de producció. Amb

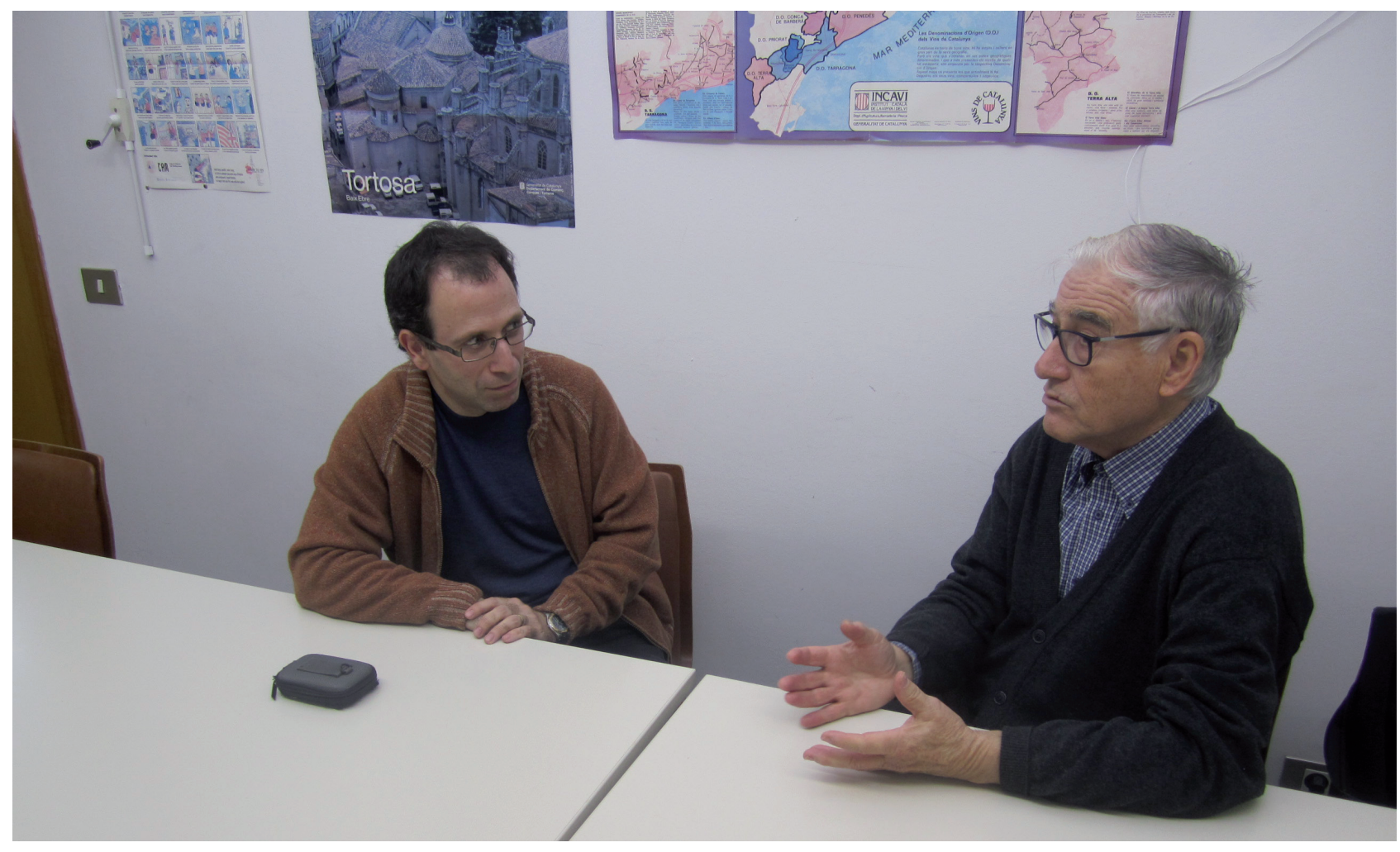


el grup de recerca de la URV (amb Lola Garcia, Cori Camps, Emília Molas i Fabia Morales, entre d'altres) hem treballat darrerament sobre la gestió eficaç de l'ensenyança i l'aprenentatge universitari en el context dels nous graus.

Aprofito per agrair-los, des d'aquí, i també a tots els companys i companyes professors, les atencions rebudes i tot el que he après d'ells.

La teva especialitat és la psicologia de l'educació, i s'acostuma a dir que aquesta àrea és una de les bases de les ciències de l'educació, junt amb la pedagogia i les didàctiques específiques. Quina és l'aportació essencial que fa la psicologia de l'educació?

He fet onze assignatures diferents al llarg dels anys a la universitat, però és cert que pràcticament des dels inicis he impartit psicologia de l'educació. Per què se la considera essencial en la formació de mestres? Et donaré la meva justificació: perquè tractes a classe allò que hi està passant en aquell mateix moment, parles directament de l'aprenentatge i de l'ensenyança. L'estudiant pot adquirir així una bona experiència.

M'ho he passat molt bé ajudant a prendre consciència del que ens estava passant realment durant la classe: que es produien canvis entre el que els estudiants sabien abans i el que saben al final; que es podien plantejar assolir diverses metes i explicar així la motivació ficada; que hi havia factors personals o relacionals que influïen en l'aprenentatge que es feia; que s'interactuava amb formes i recursos de tot tipus, verbals principalment; etc. De tot això, la psicologia de l'educació en fa tema: aprenentatge significatiu, motivació, canvi en coneixements previs, discurs de l'aula, representacions i expectatives, interaccions mestre-alumne, $o$ altres.

Sempre he dit que és una sort per a la formació personal i professional poder reflexionar molt sobre el que testà passant en aquell precís moment. Per això aquest enfocament de l'assignatura de cara a la formació dels mestres.

Potser sí que és una sort, com dius, impartir aquesta assignatura; però no creus que massa sovint, a la Universitat, "diem el que s'ha de fer, sense fer-ho"? És a dir, expliquem de manera te- òrica com ha de ser l'ensenyament-aprenentatge però no acabem de donar exemple a l'aula?

És una crítica que es fa sovint, cert. Però no en sé l'abast exacte. No en totes les matèries has d'explicar necessàriament com ha de ser l'ensenyament i aprenentatge. En d'altres, sí. En aquestes, ser coherent entre el que prediques i el que fas no és una virtut que tens o no tens del tot. Depèn de si tens consciència o no en tot moment de la necessitat de ser conseqüent, o de si tens a mà recursos per demostrar coherència, o del grau de compromís amb la docència que tinguis o vulguis tenir. Depèn molt de cadascú.

He pogut entendre, per exemple, que no podia demanar als meus estudiants que fessin diari de classe si jo no el feia, que no podia indicar-los que el bon mestre havia de saber el nom dels seus alumnes el primer dia si jo no mespavilava per fer-ho amb ells; que no podia dir-los que hi ha estratègies per motivar l'alumnat de les escoles, si jo no les feia servir; que hi havia tota una sèrie de recursos comunicatius i lingüístics per ajudar a construir el coneixement si no preníem consciència que jo els utilitzava a classe. Però segur que se'm passaven per alt moltes altres ocasions per mostrar coherència entre el que deia i el que feia.

D’altra banda, cal fer més necessària i obligatòria la preparació docent del professorat dels graus de Mestre. A vegades es viu només de la bona voluntat de les persones, del que s'ha après a corre-cuita, del que s'ha llegit en l'última revista, del que s'ha vist fer a la universitat mentre s'estudiava. I agreujat, potser, pel problema de les acreditacions en recerca, que impedeixen pensar en la qualitat de la docència.

En una entrevista sempre és interessant conèixer l'opinió de l'entrevistat en diversos temes, i volem seguir amb la formació dels futurs mestres. Amb la perspectiva que et dóna la teva experiència, creus que en general els formem prou bé?

Mai es pot dir que la formació donada i rebuda és suficient. En el cas de la dels mestres, des de la meva experiència, crec que els nivells d'exigència en la formació inicial haurien de ser més elevats. He estat sovint pessimista sobre si valia prou la pena el que sofereix als estudiants de Mestre durant els quatre (abans, tres) anys de carrera. Una 
de les afirmacions que sempre m'ha dolgut més escoltar, en aquest sentit, és la dels estudiants tornats de les primeres pràctiques escolars dient que allà sí que havien aprés de què anava la professió de mestre; em feia preguntar amb amargor què els donem aquí, que hagin d'anar fora per descobrir-ho!

Pot consolar una mica adonar-se que, entre nosaltres, deu costar molt quedar mínimament satisfets, perquè el dubte sobre el nivell de la formació inicial dels mestres l'he vist plantejat i mai esvait al llarg dels trenta-nou anys que n'he estat professor.

\section{Què creus que seria millorable en la formació} inicial dels mestres i què ajudaria a elevar el nivell de la formació inicial?

No em referiré a mesures a prendre abans de començar la carrera o un cop acabada, que d'això se'n preocupen les administracions educatives: si exigència de notes més altes, si proves específiques, si més anys de pràctiques, si un MIR com els dels metges... Ni tampoc vull referir-me a la formació dels formadors de mestres, que fem o hem fet el que hem pogut o sabut.

Centraré la resposta a la teva pregunta en un aspecte que considero clau per millorar-la: dic que la qualitat docent depèn molt de l'organització, que organitzar bé la docència és un aspecte clau per millorar-la.

En algun temps havia pensat idealment que lèxit depenia exclusivament del mestre o del professor i del seu mètode, i deixava en segon terme aspectes organitzatius. Ara no.

Recullo exemples, que coneixem prou, citant els quals em puc fer impertinent, però és que ho tinc clar!: com es pot centrar l'ensenyança en l'estudiant - màxima bolonyesa- si en tens més de 80 a classe?; com es pot fer avaluació continuada -ídem- si no pots tenir una dedicació màxima com a professor? Si interioritzar el coneixement requereix temps, pausa, lentitud, com es pot fer això si la majoria d'assignatures dels plans s'han de cursar en molts pocs mesos, si les vivim acceleradament, si no es torna a temes tractats potser mai més? Si es diu que la coordinació del professorat i la revisió conjunta del que es fa són aspectes clau per a la millora de la qualitat do- cent, ¿com ho faràs amb un nombre tant elevat de professorat que no es poden dedicar amb més exclusivitat a la universitat, o si no s'acompanya prou al professor universitari novell?

\section{Però no creus que hi ha hagut millores significa-} tives els últims anys?

Més enllà dels retrets anteriors, sí que he trobat propostes significatives de millora. Per a mi, un canvi positiu ha estat considerar la realització d'activitats pràctiques que formen part integral del disseny de l'assignatura i no són un afegit. Segur que no es pot generalitzar a la universitat que tothom faci treball per projectes o aprenentatge basat en problemes - mostres clares de com posar les activitats ben en primer pla-, però Déu n'hi do com s'insisteix que l'estudiant posi en pràctica el que aprèn, i no només que adquireixi coneixement.

En aquest sentit, matreviria a suggerir que s'estableixi com a línia de treball prioritari des de les coordinacions dels ensenyaments de Mestre el tema de les activitats per acordar més quines, per què, quan i com es dissenyen i avaluen.

Una altra proposta de millora que em sembla significativa és el fet de redescobrir l'estudiant com a protagonista, com a responsable primer de la seva formació. Però, com he dit abans, hi ha massa obstacles que ho dificulten i que fan que la proposta sembli només cosa retòrica, de no poder passar del paper on està escrita a la realitat. També es podria avançar per aquí, per assegurar millors acompanyaments o guiatges als estudiants, més personalització dels seus aprenentatges.

En general, quins elements haurien de ser imprescindibles, haurien de quedar del tot assegurats, en la preparació dels estudiants dels graus d'Educació Infantil i d'Educació Primària?

És difícil afegir alguna cosa nova a tot el que s'ha dit sobre com ha de ser un mestre. Penso que tothom estaria d'acord, en general, que un estudiant dels graus de Mestre ha de sortir sent competent en aquests quatre àmbits: 1 . La comprensió del fet educatiu en el període de 0-6 anys o de 6-12, i dels processos psicològics, d'aprenentatge i de construcció de la personalitat; 2 . La planificació i el seguiment dels aprenentatges de l'alumnat; 
3. La participació en la gestió i l'establiment de relacions interpersonals amb l'entorn familiar $i$ social; 4. Lassumpció de deures i responsabilitats relacionats amb desenvolupament personal i professional. Aquests quatre eixos són els que he utilitzat darrerament per agrupar les onze o dotze competències assenyalades en les directrius del BOE per a la formació del Mestre (per cert, redactades, al meu entendre, de manera bastant horrorosa). Però, dit així, sona a massa general, sona a poc. És com si diguéssim que és bàsic o imprescindible aprendre a fer de mestre en tots els seus vessants professionals.

\section{Podries concretar-ho més?}

Una selecció més acurada del que és bàsic aprendre hauria d'estar passada per diversos filtres, com ens recordàvem quan elaboràvem els currículums de la Reforma.

I en els moments presents, més que atendre criteris de disciplina - tal com ha estat l'habitual-, crec que el filtre principal per decidir el bàsic o imprescindible en la formació de mestres és atendre preferentment les característiques del món en el qual viuen i viuran els nois i noies d'avui en dia. Per a mi, aquesta seria la font primera per decidir el bàsic ara.

Com ho concreto? No estic imaginant uns plans docents alternatius del tot als actuals. No dic que els estudiants de Mestre deixin d'aprofundir en el coneixement matemàtic, de les llengües, de com és el món natural i social, de com es desenvolupen i aprenen els nois i noies, de com sorganitza l'escola, de quines metodologies són adients $\mathrm{o}$ altres matèries bàsiques. No caldria canviar gaire els plans docents vigents si amb els continguts de les matèries féssim el següent: ajudar els estudiants de Mestre sobretot a pensar-los més, a relativitzar-los, a saber-los comunicar, a recrear-los, a sentir emocions quan els tracten, a establir-los en xarxes de coneixements amples... És que el món d'avui i el previsible de demà, el dels nois i noies futurs alumnes, demana més saber comunicar, informar-se amb criteri, saber buscar i trobar, ser flexible, ser creatius, estar preparat davant la incertesa!

Com veus, poso l'accent a fomentar actituds com aquestes en els estudiants dels graus de
Mestre, per a un bon exercici professional futur. Considero que haurien de quedar del tot assegurades en la seva formació.

També seria imprescindible, com en qualsevol àmbit formatiu, assegurar el desenvolupament personal equilibrat de l'estudiant, i el que facilita poder accedir a altres processos formatius posteriors.

Però què és imprescindible i què prescindible sempre serà un tema obert: és una pregunta que ens fem cada dia els docents, oi? Ho expressa assenyadament una diapositiva que he passat moltes vegades a les classes, en la qual un professor i un alumne pensen el mateix, però amb paraules diferents: per què he d'aprendre això?, diu l'un; per què he d'ensenyar això?, diu l'altre.

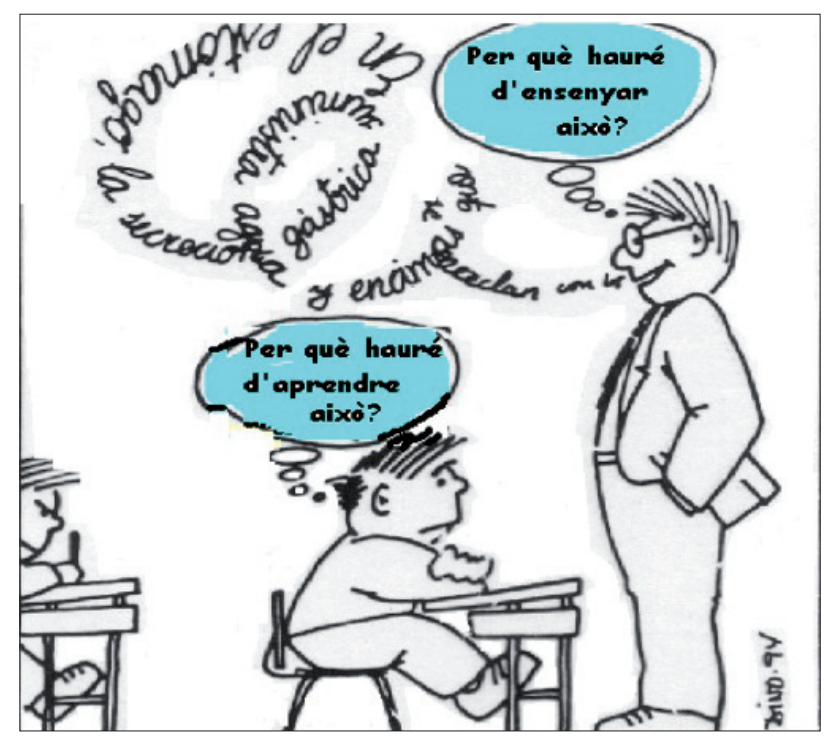

Fa algun temps que en els nostres models formatius s'hi ha incorporat el concepte de "competència", sobre el qual has treballat. I el cert és que aquesta paraula, "competència", continua generant certa confusió, vinculant-la a un model de societat competitiu i centrat en la formació de mà d'obra. Quina valoració fas dels canvis que hi ha hagut en els darrers anys? Un bon docent no ha treballat sempre per competències, encara que no conegués la paraula?

La confusió creada sobre el terme competència crec que és interessada. M'explico. Apareixen els currículums competencials en totes les etapes educatives arreu del món perquè s'assumeix que saber només per saber no porta enlloc 
avui — perquè ho pots trobar a Internet! —, i que, en tot cas, acumular sabers hauria de servir més per poder fer alguna cosa amb aquests sabers. Com, per exemple, donar solució als mil problemes quotidians, que això no ho trobes a Internet. Aquesta, i no cap altra, és la versió que entenc que cal atorgar a les competències dels currículums de totes les etapes educatives, i aquesta és l'orientació a donar al treball docent a les escoles i a la universitat si volem preparar per viure en el segle XxI. Aquest seria l'esperit dels canvis recents.

Una altra cosa és la lletra, tota la parafernàlia formal muntada per programar-les endreçadament en els processos d'ensenyança, aprenentatge i avaluació.

¿Si els bons docents han treballat sempre per competències? Si han buscat contínuament la utilitat i aplicació dels coneixements que els estudiants aprenien, llavors et dic que sí.

\section{I com caldria avaluar efectivament per compe- tències?}

Constato que l'avaluació de les competències s'ha convertit, per a molts docents de primària, de secundària i d'universitat, en el problema principal relacionat amb les noves propostes. Penso, en canvi, que aquest seria un problema relativament menor si com a docents es tingués més clar què són les competències - en general, i cada una de les que consten en les directrius acadèmiques $\mathrm{i}$ en els currículums de les etapes educatives- i, sobretot, què significa dur a terme uns currículums competencials. Veure-hi més clar en aquest assumpte segur que faria més fàcil potenciar $\mathrm{i}$ avaluar competències.

Intento contestar la pregunta directa que em fas, un tema que he hagut de treballar sobretot en la formació permanent del professorat. Parteixo d'una premissa molt simple, que abans ja he insinuat: que si ser competent vol dir ser capaç d'actuar en situacions diverses aplicant els coneixements apresos de manera eficaç i estratègica, llavors avaluar competències consistirà a informar-se de com es posen en pràctica els coneixements adquirits. Es poden avaluar sabers concrets o aillats per veure si estan consolidats - cosa important de fer-, però encara no s'estan avaluant competències si no planteges situacions i activitats concretes per veure la seva aplicació, com es fan servir. He entès que aquesta és la diferència clau entre l'avaluació d'abans i la que ara es reclama, el pas a fer, tot superant la trampa tradicional que diu que si saps bé la teoria, automàticament ja saps posar-la en pràctica, que si saps bé els continguts ja saps aplicar-los.

Ja sé que no es pot detallar molt, però et pregunto com ho has portat efectivament a la pràctica en les assignatures que has impartit darrerament.

Aporto el que he fet. Deixa'm dir abans que reconec que em considero privilegiat per haver pogut dur-la a terme així, i que no tothom es troba en condicions semblants a les que he aconseguit: assignatures ideals, nombre normal d'estudiants, acceptació de bon grat per part d'ells del sistema d'avaluació que els proposava.

Què he fet? Primer, preparar bé el que he anomenat programa avaluatiu de l'assignatura, amb la relació de les activitats d'avaluació pensades per a cada mòdul de treball. Per a una assignatura de tres mòduls, per exemple, planificava un total de vuit o nou i activitats, entre les individuals i les fetes en grup.

Segon, confeccionava quadres - un per a cada mòdul- on es veiés la relació entre les competències a assolir amb el treball de l'assignatura $i$ cada una de les activitats d'avaluació. En aquest sentit, a diferència del que recordo que es proposa en les guies per elaborar els plans docents de la URV, he preferit que les competències es relacionessin directament amb les activitats pràctiques i no amb les metodologies.

Tercer, cada vegada que presentava una activitat d'avaluació als estudiants feia explícites diverses indicacions per implicar més els estudiants en l'avaluació: els processos principals sol-licitats, el producte principal a presentar, la competència $o$ competències que s'avaluaven, els criteris d'avaluació o resultats d'aprenentatge esperats, $\mathrm{o}$ altres orientacions de caire més organitzatiu.

Un cop corregides i qualificades les activitats, feia el corresponent retorn dels resultats, i suggeria mesures a prendre per millorar els aprenentatges i el desenvolupament de les competències. 
He de reconèixer que no feia servir directament rúbriques, tal com les coneixem. He assistit a congressos sobre rúbriques, he seguit el tema i he quedat una mica decebut, perquè generalment hi ha com certa inconsistència o superficialitat en la concreció dels nivells i, sobretot, perquè no s'acostumen a tenir en compte criteris de seqüenciació dels aprenentatges. Ara ja no tinc ocasió d'aprofundir en el tema.

Has parlat d'una situació propícia per fer una avaluació efectiva de les competències. Què creus que es podria fer per assegurar-la i que pogués generalitzar-se més?

Insisteixo que el que he fet és una de les moltes maneres de dur a terme l'avaluació de competències, igual de respectables i efectives.

Per on avançar? He vist que allà on s'ha proposat seriosament avaluar competències hi havia coordinació entre els docents que potenciaven i avaluaven el desenvolupament de la mateixa o mateixes competències en els estudiants, almenys pel que fa a la selecció de les activitats d'avaluació escollides. Si diversos professors es plantegen desenvolupar i avaluar la mateixa competència, sembla lògic un acord previ per decidir situacions i activitats d'avaluació adients i ordenades.

D’altra banda, segueixo pensant que és bastant impossible dur a terme formes efectives d'avaluar competències amb massa estudiants per aula. No he deixat d'insistir allà on he pogut que un nombre excessiu d'alumnes és incompatible amb poder fer una raonable avaluació de competències, perquè genera molta feina al professorat $\mathrm{i}$ molts dubtes, atès que no pots fer un seguiment acurat del progrés o estancament dels estudiants, o perquè només t'has de limitar a avaluar algun aspecte molt parcial del desenvolupament competencial.

\begin{tabular}{|c|c|c|c|c|c|c|c|c|c|}
\hline \multicolumn{10}{|c|}{ Programa avaluatiu del Mòdul 1: Immigració i contacte entre cultures } \\
\hline \multicolumn{2}{|r|}{$\begin{array}{c}\text { Situacions i activitats } \\
\text { d'avaluació }\end{array}$} & \multirow{2}{*}{$\begin{array}{l}\text { Resposta a si } \\
\text { cal plantejar- } \\
\text { se la gestió de } \\
\text { la diversitat } \\
\text { en Educ. Inf. }\end{array}$} & \multirow{2}{*}{$\begin{array}{l}\text { Discussió sobre } \\
\text { accés, drets } i \\
\text { llihertats } \\
\text { ciutadians } \\
\text { estrangers }\end{array}$} & \multirow{2}{*}{$\begin{array}{c}\text { Recull de } \\
\text { dades de } \\
\text { pollacio } \\
\text { estranger } \\
\text { at }\end{array}$} & \multirow{2}{*}{$\begin{array}{l}\text { Treball per } \\
\text { desmitificar } \\
\text { rumors selore } \\
\text { cel.lectius }\end{array}$} & \multirow{2}{*}{$\begin{array}{c}\text { Tasques a } \\
\text { partir de } \\
\text { "Posarse en la } \\
\text { pell d' un } \\
\text { immuigrunt" }\end{array}$} & \multirow{2}{*}{$\begin{array}{c}\text { Quadre } \\
\text { comparatiu } \\
\text { multicultural. } \\
\text { iinterculturali } \\
.\end{array}$} & \multirow{2}{*}{$\begin{array}{l}\text { Rexum } \\
\text { dliscussiá } \\
\text { sobre tema } \\
\text { burca }\end{array}$} & \multirow{2}{*}{ Carpeta } \\
\hline & Competències & & & & & & & & \\
\hline i & $\begin{array}{l}\text { Comprendre la funció, les } \\
\text { possibilitats i els limits de } \\
\text { leducació a la societat actual }\end{array}$ & $\mathrm{x}$ & $\mathrm{x}$ & & & & & $\mathrm{x}$ & $\mathrm{x}$ \\
\hline \multirow{5}{*}{$\stackrel{*}{*}$} & $\begin{array}{l}\text { Promoure aprenent. integrant } \\
\text { dimensi. cognita, emocional... }\end{array}$ & & & & & & & $x$ & $\mathbf{x}$ \\
\hline & $\begin{array}{l}\text { Dissenyar espais atenguin } \\
\text { necessit educati., igualtat, } \\
\text { equitat, respecte drets }\end{array}$ & & & & & & & $x$ & \\
\hline & $\begin{array}{c}\text { Aplicar pensament critic, } \\
\text { Iógic i creatiu }\end{array}$ & $\mathrm{x}$ & $x$ & & & $x$ & & $x$ & $x$ \\
\hline & $\begin{array}{c}\text { Comunicar informació, } \\
\text { idees, ... de manera clara i } \\
\text { efectiva }\end{array}$ & & & $\mathrm{x}$ & $\mathbf{x}$ & $\mathbf{x}$ & & $\mathbf{x}$ & $\mathbf{x}$ \\
\hline & $\begin{array}{l}\text { Gestionar informació i } \\
\text { coneixement }\end{array}$ & & $x$ & $x$ & & $x$ & $\mathrm{x}$ & $x$ & $x$ \\
\hline \multirow{3}{*}{ in } & $\begin{array}{l}\text { Actuar com orientador en } 0.6 \mathrm{i} \\
\text { dominar tracte families }\end{array}$ & & & & & & & & \\
\hline & $\begin{array}{l}\text { Reflexionar sobre acceptació } \\
\text { normes i respecte als altres }\end{array}$ & & $x$ & & $\mathbf{x}$ & $\mathbf{x}$ & & & \\
\hline & $\begin{array}{l}\text { Treballar en equip de forma } \\
\text { col.laborativa i responsable }\end{array}$ & & & $x$ & $x$ & & & & \\
\hline \multirow{6}{*}{ : } & Fomentar la convivència & & $\mathrm{x}$ & & $x$ & & & & \\
\hline & \begin{tabular}{|c|}
$\begin{array}{c}\text { Promoure educació emocions, } \\
\text { sentiments, valors }\end{array}$ \\
\end{tabular} & & & & & & & & \\
\hline & A prendre a aprendre & & & $x$ & $x$ & & $x$ & & $x$ \\
\hline & $\begin{array}{l}\text { Resoldre problemes } \\
\text { complexos en l'ämbit El }\end{array}$ & $x$ & & & & & & & \\
\hline & \begin{tabular}{|c|} 
Treballar autònomament amb \\
responsabilitat $\mathrm{i}$ iniciativa
\end{tabular} & & & & & $x$ & $x$ & $x$ & $x$ \\
\hline & $\begin{array}{l}\text { Comprometre's amb ètica i } \\
\text { responsabilitat social }\end{array}$ & & $x$ & & $x$ & $x$ & & $x$ & $x$ \\
\hline
\end{tabular}


Per imperatiu legal, fa poc t'has hagut de jubilar. Sabem que tenies $i$ tens una visió del que hauria de ser una autèntica facultat per formar mestres. ¿Podries dir-nos quins canvis creus que no es van fer en algun moment a la URV per aconseguir-ho i quins caldria activar?

Em fa no sé què parlar d'això quan ja en sóc fora, si no ho vaig fer prou quan era dintre. Però respondré el que em preguntes.

De vegades hem recordat amb companys i companyes que vàrem viure el pas d'Escola de Mestres a Facultat com en va ser de traumàtic, als anys noranta. Exagerant una mica, l'he interpretat com un xoc de cultures. La de l'Escola de Mestres era, possiblement, tancada i amb requisits acadèmics universitaris a millorar; però s'hi valoraven molt aspectes que sempre he considerat claus en la formació de mestres: es valorava molt la docència, com a tal; hi havia un projecte de centre - en conservo el document- que orientava la formació; existien equips despecialitat, de curs, per assegurar més coordinació; hi havia expressament dissenyats espais i horaris per als intercanvis, per a la discussió, per fer coneixement d'experiències escolars; estava arrelada una mena de consciència col-lectiva que allí s'hi formaven mestres i que calia que tothom anés en aquella direcció.

Hi ha guanys d'aquests que amb els anys s'han recuperat en la Facultat, i d'altres potser no. I, alhora, han aparegut altres dinàmiques tant $o$ més positives.

\section{A banda de la referència a la història que acabes de fer, podries resumir mesures concretes que des del teu punt de vista caldria activar més?}

Recordo, primer, alguna que ja ha sortit abans a l'entrevista: revisar sovint què s'ensenya, què cal que els estudiants aprenguin ben significativament, el que és imprescindible en els programes i el que no. Això comporta revitalitzar grups i processos de discussió, reflexió i presa d’acords collectius sobre continguts, sí, però indirectament també permet parlar de la professió de mestre i la seva formació, o de la qualitat de la docència. Ha de ser fàcil organitzar-ho, o potenciar-ho.

Una altra mesura. A veure si sé explicar-me. A vegades he tingut la impressió que a la Facultat jugàvem molt a fer com si: com si treballéssim en equip, com si féssim avaluació contínua, com si seguíssim els plans docents, com si treballéssim per competències, com si féssim bones tutories, com si donant bibliografia, aquesta ja es consultava... I tot això, perquè teníem formalitzat en documents o en el Moodle la programació de les assignatures, la relació de competències, les guies del treball final, les valoracions dels pràcticums, $o$ altres. "Si està formalitzat, ja és suficient", sembla que acceptàvem implícitament, tot i saber que no és així. Penso que caldria, a banda del formal, entrar més a fons en l'important a l'hora d'emmarcar la formació: centrar-se preferentment en què passa o hauria de passar realment a l'aula, mentre s'ensenya i aprèn. Costa parlar-ne i explicitar-ho, efectivament.

No puc acabar sense fer-te una pregunta personal, com a professional compromès, que has estat un professor de referència a les aules de Magisteri: què t'ha aportat el món de l'educació com a professor i com a persona?

He, he. Difícil de contestar. A més, com que encara no m'he acabat de fer a la idea de la jubilació total, no he fet l'exercici ordenat de repassar com m'ha influit personalment la dedicació al món educatiu. Per tant, el que diré no és definitiu.

Se m'acut referir-me, primer, a unes aportacions curioses.

Que m'ha permès conèixer directament uns 5.000 estudiants, pel cap baix. Déu n’hi do! Aprofito per agrair-los, des d'aquí, el reconeixement rebut, la proximitat que m'han brindat i que hagin volgut fer també seves les meves exigències

Que he pogut seguir totes les etapes de l'entrada de les tecnologies en l'ensenyança: materials fets amb clixés escrits a màquina, materials fets amb clixés electrònics, transparències en blanc i negre, materials fotocopiats, transparències en color, diapositives normals, presentacions fetes en PowerPoint (guardo moltes col-leccions de diapositives: gràcies, Frato i Tino!) i Internet a l'aula.

Que això de treballar amb gent jove et fa creure que segueixes jove tota la vida

A un altre nivell, més enllà de les altres tasques a què obliga ser professor universitari, la 
dedicació al món educatiu m’ha permès viure cada dia una experiència que considero única, l'experiència precisament de la docència. Per a mi ha estat una experiència cada cop més conscienciada i valorada, amb el pas dels anys. M'ha permès - obligat-, per exemple, a estar al dia quant al coneixement; a tenir preparades per escrit totes les classes; a ser clar i ordenat en el parlar, el que deia i el com ho deia; a aprendre a estar al costat de cada estudiant o de cada grup guiant i exigint, però sense amoïnar-los del tot; a haver d'encertar sobre la marxa quin podia ser un bon exemple, una resposta adient a la pregunta, un estímul motivador, una activitat adequada a fer, un consell oportú davant l'èxit o el fracàs; a acceptar l'exposició contínua a la crítica, i a tolerar-la; i altres requeriments.

Ara mateix que rememoro experiències com aquestes, he tornat a sentir-me satisfet.

Però també em queda un regust una mica amarg de l'experiència docent: no em deixa tranquil la idea de si he contribuït prou a la formació de cada un dels meus estudiants, si hauria pogut fer molt més.

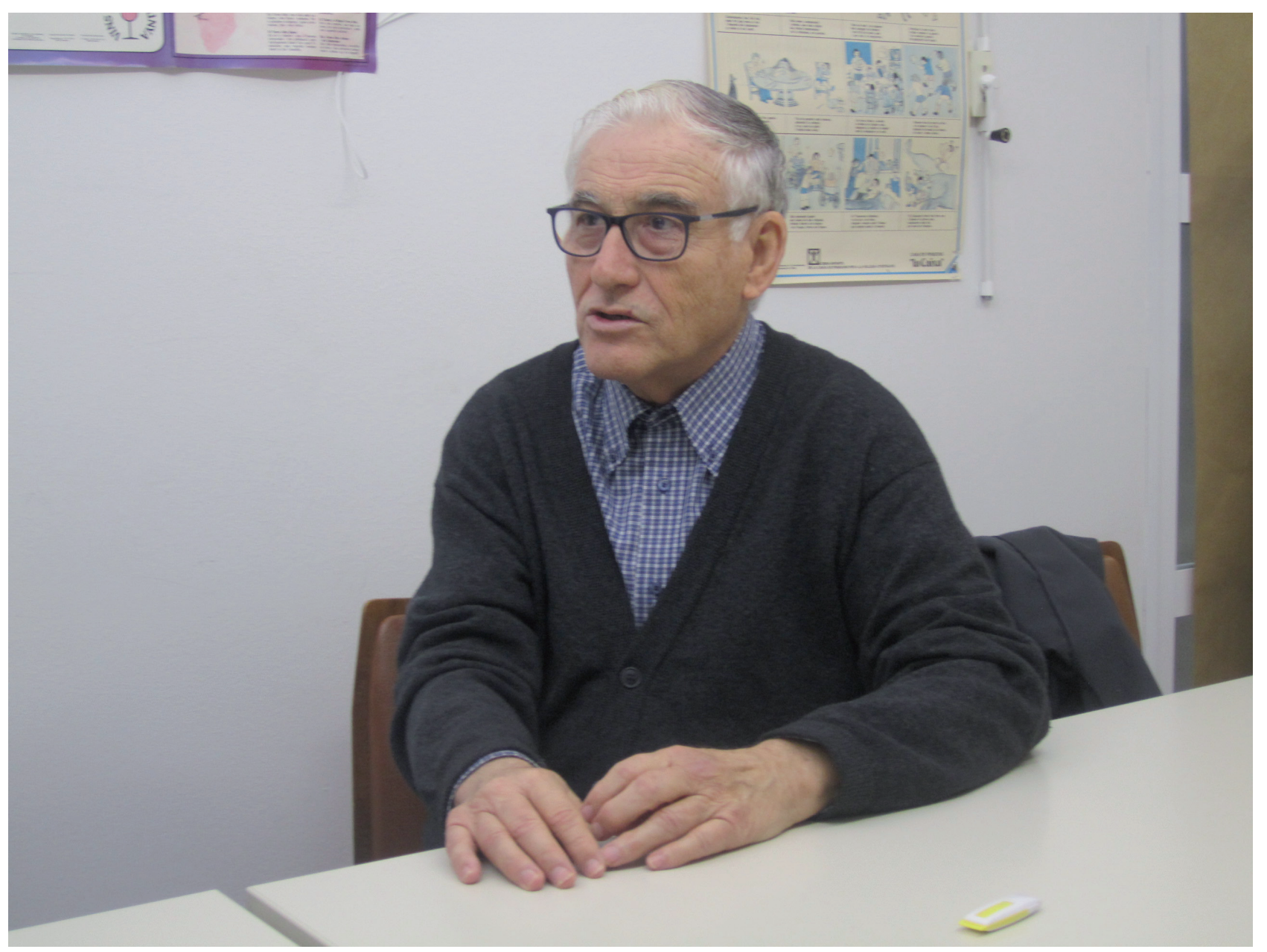

